\title{
Initial knowledge of college-level introductory geology students in the United States
}

Steven W. Anderson \& Amanda Manzanares

Department of Earth and Atmospheric Sciences, The University of Northern Colorado, Greeley, Colorado 80639 uSA

E-malls: steven.Anderson@unco.edu, Amanda.Manzanares@unco.edu

Abstract: The initial knowledge of college-level introductory geoscience students is poorly understood, yet greatly affects the ability of instructors to create an effective learning environment. Here we review past research into several fundamental $\mathrm{GeO}$ science concept areas to better understand misconceptions, alternative conceptions and preconceptions related to Geologic Time, Plate Tectonics and geohazards. We combine this review of past work with new research on what students understand about minerals in order to address the disconnect between instructors ' perceptions of their students ' initial knowledge, with what the students actually understand, in order to create a basis for decisions on course structure and pedagogy.
Manuscript:

Received: Quadrennial Conference of the International Geoscience Education Organization

Accepted:12/08/2018

Citation: Anderson S. W., Manzanares .A. 2018. Initial knowledge of college-level introductory geology students in the United States Terræ Didatica, 14(3):326329. URL: http://www.ige.unicamp.br/terraedidatica/.

Keywords: Misconceptions, preconceptions, alternative-conceptions

Thematic line: Education, Teaching of Geosciences and Teacher Training

\section{Introduction}

Understanding the initial knowledge of college students entering introductory geology courses allows instructors to consider how to structure lessons and activities to elicit the best possible learning response. However, several studies show a significant disconnect between the instructors' perceptions of their students' knowledge state, and the actual knowledge state of students in introductory geology courses, (Libarkin et al. 2002, Libarkin \& Anderson 2005). Libarkin \& Anderson (2005) asked instructors to comment on the value of multiple choice questions designed to test student understanding in the geosciences, and found that many greatly overestimated their students' knowledge. For example, one instructor lamented "does any rational adult not believe that the Earth has a magnetic field", and yet several students chose that incorrect answer when tested. This disconnect can result in instructors skipping over necessary background information, spending insufficient class time on basic concepts, creating exams and individual test questions that are too difficult to assess learning, moving on to more difficult concepts before a solid conceptual foundation is established, and having unreasonable expectations for class and individual student performance.
In this paper we consider past and new research on student learning in the Geosciences that sheds light on the initial knowledge state of introductory college-level Geoscience students, focusing on common misconceptions, alternative-conceptions, and preconceptions that exist in this student population.

An understanding of the initial knowledge state of introductory college-level Geoscience students should enable instructors to consider how to approach course structure and pedagogy for the maximum learning effect.

\section{Past Research}

\subsection{Fundamental Concepts in the Geosciences - Previous Work}

Although there are no exhaustive studies of the initial Geoscience knowledge state of college-level students, a number of studies have probed misconceptions, preconceptions and alternative conceptions of students in several topic areas covered in most introductory Geoscience courses (see Leonard et al. 2014) for a thorough review of these terms). Dove (1998) and Cheek (2010) provide literature reviews on student conception research 
in the Earth sciences that span a large age range from pre-K to post-college. Here, we will focus on those studies limited to college students, including pre-service teachers.

The Dove (1998) and Cheek (2010) review articles covering studies of student conceptions shows that college-student studies are limited to a few concept areas. College student perceptions of Geologic Time has received attention from several researchers. Gosselin \& Macklem-Hurst (2002) explored the Earth history conceptions of pre-service teachers, and found that although most students knew the surface of the Earth has changed over time, less than half knew the scientifically accepted age of the Earth. Other studies have shown that even if the student knows the accepted age of the Earth, they may not truly understand the difference between thousands, millions, and billions of years (Libarkin et al. 2007). Libarkin et al. (2007) also found that students could generally place a series of events that included Earth formation, formation of first life forms, and the evolution of dinosaurs and humans, into the correct order, but had little understanding of the scale of time between events. They also found a significant number of students who believed dinosaurs and humans coexisted on Earth for a period of time, and a small number of students who believed the Earth was quite young (thousands of years old). Students were generally more comfortable with questions on relative time and events than those focusing on absolute time, and struggled with the scale of time. This mirrors similar studies in younger populations (Cheek 2010), and serves as the impetus for many of the works found in a special issue of the Journal of Geoscience Education devoted specifically to the teaching of time (January 2001).

A considerable amount of research has also focused on the Earth's interior and how it affects surficial processes such as plate tectonics and volcanoes. Libarkin et al. (2005) and Libarkin \& Kurdziel (2006) found that college students struggled with locating the Earth's tectonic plates. Most students, when asked to draw the location of plates on a cross section of the Earth, placed the upper surface of the plate well beneath the Earth's surface, and occasionally well above the surface, effectively removing them from direct contact with humans (Figure 1, from Libarkin et al. 2005). Again, students seem to struggle with scale, unable to related their personal surroundings with the larger space occupied by the Earth (Libarkin et al. 2005).

Students also struggled with how the Earth's interior works, and how it affects surface processes. Libarkin et al. (2005) found that a substantial number of students believed magma originates in the Earth's core, perhaps conflating the geologic definition of core with everyday language where "core" refers generally to the interior. This conflation of everyday notions with scientific explanations was noted as a common theme in both the Dove (1998) and Cheek (2010) review articles, and should give educators pause when casual using scientific terms and jargon in a classroom setting without adequate explanation.

Additionally, students seemed to also struggle with the scale of physical parameters, such as temperature. Libarkin et al. (2005) noticed a curious
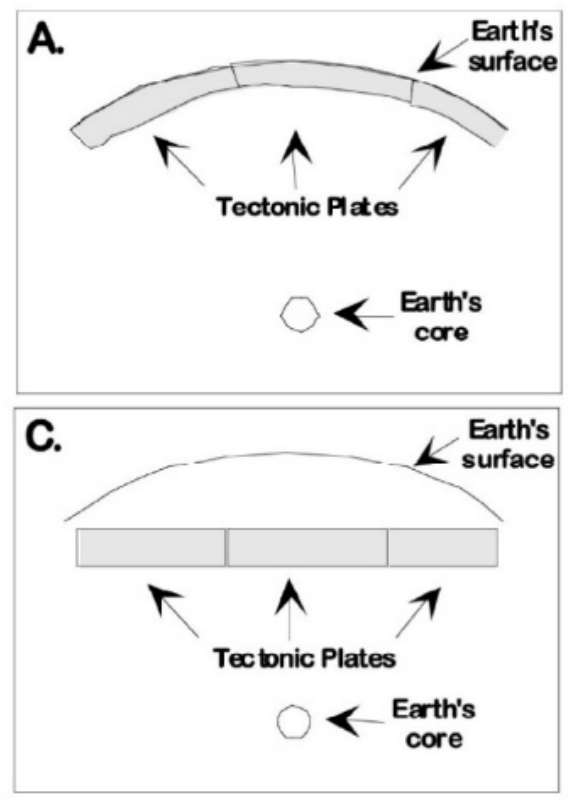

Figure 1. Schematic view of student ideas regarding tectonic plates from Libarkin et al. (2005). Note that "A", the scientific perspective where plates extend to the Earth's surface, was rarely described by college students during in-depth interviews
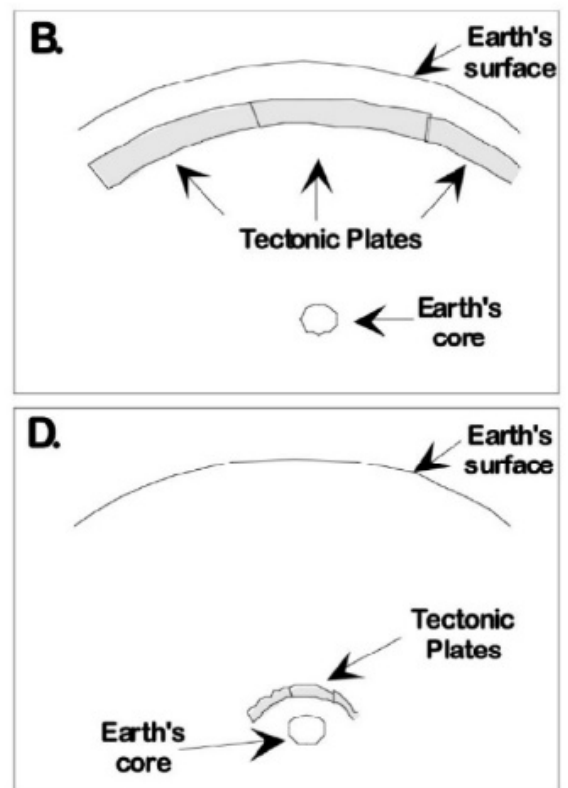

\begin{tabular}{c|c|c|c|c|c}
\hline (C) Terrae Didat. & Campinas, SP & v.14 & n.3 & p. 326-329 & jul./set. 2018 \\
\hline
\end{tabular}


reoccurrence in student drawings regarding the placement of volcanoes on the Earth's surface. Whereas many students placed volcanoes on the edge of continents (sometimes all continental margins, not just those with active subduction zones) they noticed a small but significant number of drawings showing volcanoes in equatorial settings. When probed during interviews, explanations such as "it's hotter there" shows students conflating atmospheric temperatures with volcanic activity, and failing to realize that one process is incapable of significantly affecting the temperature of the other.

One additional conceptual theme noted by Cheek (2010) that may be common to a number of studies is that students often ascribe animate characteristics to explain geologic processes. For example, Libarkin et al. (2005) noted that a significant number of students believed that older mountains are taller than younger mountains because they have had more time to grow, and that the Earth will become larger as time goes on. Applying everyday notions to Geoscience phenomena is a major theme in many studies of college student conceptions.

Finally, we note that many of these alternative conceptions in the Earth sciences relate to temporal, spatial, and physical process scale, and that conceptual understanding of Earth science topics may rely on the students understanding of fundamental physics and chemistry. Anderson \& Libarkin (2016) used a concept test called the Geoscience Concept Inventory (GCI) (Libarkin \& Anderson 2005, 2006, 2008, Libarkin et al. 2011) to pre- and post-test thousands of students in introductory college geology courses across the United States, and found that 21 of the 73 questions showed no measurable pre- to post-test change. Of these 21 questions, over half (12) covered basic physics and chemistry. Anderson \& Libarkin (2016) suggested that students may be clinging to incorrect geologic conceptions because of their shaky basic physics and chemistry underpinnings.

\subsection{Fundamental Concepts in the Geosciences - Current Research}

Here we report on an ongoing study that investigates the initial knowledge state of students with respect to mineral identification. Mineral identification is a fundamental skill taught in nearly every introductory geoscience lab in the United States. A perusal of 6 published physical geology lab manuals all contained mineral identification as one of the first labs presented.

Previous studies have shown some common themes with respect to college student mineral and rock. Kusnick (2002) noted that some university students ascribed living traits to rocks and minerals, believing that pebbles grow into rocks with time. In addition, some students viewed word pairs, such as mineral and rocks, as synonymous.

Because of the importance geologists place on mineral and rock identification, understanding the initial knowledge state of college-level students entering geoscience courses is necessary to properly gauge the level of background, and points of emphasis, when providing background information on the topic and guidance on how to identify minerals in a lab setting. If instructors overestimate their students' initial knowledge of minerals, and lack awareness of some of the fundamental alternative conceptions that students may bring to the lab setting, they may miss necessary steps to properly prepare students for the lesson.

We are in the process of interviewing students at the University of Northern Colorado to better understand their ideas about minerals. In 2017, we developed an interview protocol to gather information about the initial knowledge state of college students with respect to minerals. Selected students included science and non-science majors, from a variety of socioeconomic backgrounds, and varied in gender in age. None of the students had any college-level geology. We collected data on past science and math courses taken in college and pre-college.

We designed the interviews to last 30 to 40 minutes. Students were encouraged to write and draw their responses, and we taped the interviews from an angle that protected the identity of the student, yet allowed us to view their drawings and writings, and hear their oral responses to questions. Questions ranged from simple definitions of what a mineral was, how it differed from a rock, what minerals are composed of, and how they respond to sunlight, burial, water and time.

Our initial analysis shows some similarities to past published work on what students believe about minerals. We found students trying to explain minerals with everyday notions, and several tried to explain mineral growth and evolution in terms of living organisms. We saw several students try to put what they know about gemstones and crystals into a scientific context. 


\section{Conclusion}

Past research and current work point out that students entering introductory college level geology courses may 1) conflate scientific words or jargon with everyday language, 2) associate life processes to physical processes, 3 ) have insufficient understanding of basic chemistry and physics that may impede their ability to understand geoscience concepts, 4) not have a sufficient understanding of temporal and spatial scales, and may struggle with the scale of various physical parameters such as temperature, and 5) have misconceptions or poorly developed conceptions, and some may be entrenched. Understanding this initial knowledge state may enable instructors to ensure that they are 1) providing sufficient background information, especially if a basic understanding of physics, chemistry, and scale is required for understanding a concept, 2) thoroughly defining terminology that may be easily conflated with everyday language, and 3) exercising patience as students work through entrenched conceptions.

\section{References}

Anderson S.W, Libarkin J.C. 2016. Conceptual mobility and entrenchment in introductory geoscience courses: New questions regarding physics' role in learning Earth science concepts. J. Geosc. Educ., 64:74-86.

Cheek K.A. 2010. Commentary: A summary and analysis of twenty-seven years of geoscience conceptions research.J. Geosc. Educ., 58:122-134.

Dove J. 1998. Students' alternative conceptions in Earth science: A review of the research and implications for teaching and learning. Research Papers in Education, 13:183-201.
Gosselin D.C., Macklem-Hurst J.L. 2002. Pre/ Post-knowledge assessment of an Earth science course for elementary/middle school education majors. J. Geosc. Educ., 50:169-175.

Kusnick J. 2002. Growing pebbles and conceptual prisms - understanding the source of student misconceptions about rock formation. J. Geosc. Educ., 50:31-39.

Leonard, M.J., Kalinowski, S.T., and Andrews, T.C. 2014; Misconceptions yesterday, today and tomorrow. CBE, Life Sciences Education, 13:179-186.

Libarkin J.C., Ward E.M.G., Anderson S.W., Kortemeyer G., Raeburn S.P. 2011. Revisiting the GCI: A call to the community. GSA Today, 21.

Libarkin J.C., Anderson S.W. 2008, Development of the Geoscience Concept Inventory. In: National STEM Assessment Conference, Washington DC, October 19-21, 2006. Proc..., p. 148-158.

Libarkin J.C., Kurdziel J.P., Anderson S.W. 2007. College student conceptions of geological time and the disconnnect between ordering and scale. J. Geosc. Educ., 55:413-422.

Libarkin J., Kurdziel J. 2006. Ontology and the teaching of Earth system science. J. Geosc. Educ., 54:408413.

Libarkin J.C., Anderson S.W. 2006. The Geoscience Concept Inventory: Application of Rasch Analysis to Concept Inventory Development in Higher Education. In: X. Liu, ed. 2006. Rasch Applications in Science Education. JAM Publ. p. 45-73.

Libarkin J.C., Anderson S.W. 2005. Assessment of Learning in Entry-Level Geoscience Courses: Results from the Geoscience Concept Inventory. $J$. Geosc. Educ., 53:394-401.

Libarkin J.C., Anderson S.W., Dahl J., ^Beilfuss M., Boone W., Kurdziel J.P. 2005. Qualitative analysis of college students' ideas about the Earth: Interviews and open-ended questionnaires. J. Geosc. Educ., 53:17-26.

Libarkin J.C., Anderson S.W., Boone W.J., Beilfuss M., Dahl J. 2002, The Geoscience Concept Test: A new assessment tool based on student misconceptions; EOS, Trans. Am. Geophys. Union, 83. (Abstract ED11B-0047). 